\title{
Apatite halogen and hydrogen isotope constraints on the conditions of hydrothermal alteration in carbonaceous chondrites
}

\author{
MAXIME PIRALLA ${ }^{1}$, ROMAIN TARTESE ${ }^{2}$, YVES \\ MARROCCHI $^{3}$ AND KATHERINE H. JOY 4 \\ ${ }^{1} \mathrm{CRPG}, \mathrm{CNRS}$, Université de Lorraine \\ ${ }^{2}$ The University of Manchester \\ ${ }^{3} \mathrm{CRPG}, \mathrm{CNRS}-$ Université Lorraine \\ ${ }^{4}$ University of Manchester \\ Presenting Author: maxime.piralla@univ-lorraine.fr
}

Apatite has been widely used for assessing the volatile inventory and hydrothermal fluid compositions of asteroidal and planetary bodies. We measured the $\mathrm{OH}, \mathrm{F}$, and $\mathrm{Cl}$ abundances, and hydrogen isotope composition, of apatite in the C1ungrouped Bench Crater meteorite [1] and in the CM1-2 Boriskino chondrite [2]. Apatite in Bench Crater and Boriskino are halogen-poor, close to the hydroxylapatite end-member composition, and characterised by average $\delta \mathrm{D}_{\text {SMOw }}$ values of $233 \pm 92 \%$ and $-226 \pm 59 \%$, respectively [3]. Boriskino apatite might exhibit $\mathrm{H}_{2} \mathrm{O}$ incorporation with carbonate substitutions [4]. Metamorphism in Bench Crater might have caused $\mathrm{H}$ isotope fractionation, by diffusion, of apatite from an initial $\delta \mathrm{D}_{\text {SMOw }}$ value of around $130 \pm 60 \%$. The matrix in Bench Crater has a $\delta \mathrm{D}_{\text {SMOW }}$ value of $-16 \pm 119 \%$, which represents our best estimate for the $\mathrm{H}$ isotope composition of the water accreted by the Bench Crater meteorite parent body. Comparing apatite and water $\mathrm{H}$ isotope compositions yields similar apatite-water $\mathrm{D} / \mathrm{H}$ fractionation of $c a .120-150 \%$ for both carbonaceous chondrites, suggesting that apatite formed at similar temperatures. However, we cannot estimate further these formation temperatures as there is no study relating temperature and apatite-water $\mathrm{D} / \mathrm{H}$ fractionation. Combining a lattice strain partitioning model [5] with apatite $\mathrm{F}$ and $\mathrm{Cl}$ abundances in Boriskino and Bench Crater yields low $\mathrm{F}$ and $\mathrm{Cl}$ abundances < $300 \mu \mathrm{g} . \mathrm{g}^{-1}$ in apatite-forming fluids. The fluid $\mathrm{F} / \mathrm{Cl}$ ratios are consistent with the bulk $\mathrm{F} / \mathrm{Cl}$ ratios of other $\mathrm{CI}$ and $\mathrm{CM}$ chondrites, suggesting that hydrothermal alteration on these meteorite parent bodies took place under closed-system conditions. Based on the calculated $\mathrm{OH}$ abundances for the apatite-forming fluids, we estimated the $\mathrm{pH}$ values of alteration fluids to be of $c a .10$ - 13. Such alkaline fluid compositions are consistent with previous modelling and suggest that apatite formed late, towards the end of completion of hydrothermal alteration processes on the Boriskino and Bench Crater parent bodies.

[1] Joy et al. (2020), EPSL 540, 116265. [2] Verdier-Paoletti et al. (2019), MAPS 54, 1692-1709. [3] Piralla et al. (In press), MAPS. [4] Pasteris et al. (2014), Am. Mineral. 99, 16-27. [5] Kusebauch et al. (2015), GCA 170, 225-246. 